\title{
Latest Advances in the Treatment of Acute Stroke
}

\author{
An Expert Interview with Jeffrey M Katz
}

North Shore University Hospital, Manhasset, NY, US

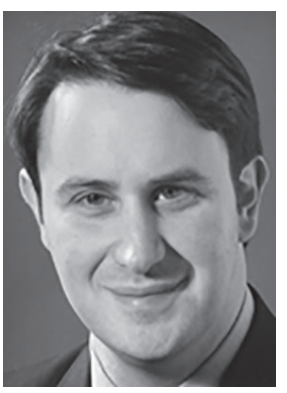

DOI: https://doi.org/10.17925/USN.2018.14.2.80

\section{Jeffrey M Katz}

Jeffrey M Katz, MD, is a vascular and interventional neurologist in Manhasset, NY. Dr Katz graduated from New York University School of Medicine in 2000; completed neurology residency, stroke and endovascular surgical neuroradiology fellowships at Weill Cornell Medical Center; and has been in practice at North Shore University Hospital for 12 years. He is an Associate Professor of Neurology and Radiology at the Zucker School of Medicine at Hofstra/Northwell and Directs the North Shore University Hospital Comprehensive Stroke Center and Stroke Unit, and the Northwell Health Telestroke Program.

\section{Keywords}

Acute stroke, endovascular treatment, embolectomy

Disclosure: Jeffrey M Katz has nothing relevant to disclose in relation to this interview.

Review Process: This is an expert interview and, as such, has not undergone the journal's standard peer review process.

Acknowledgment: Medical writing assistance was provided by Katrina Mountfort of Touch Medical Media and was supported by Touch Medical Media.

Authorship: The named author meets the Internationa Committee of Medical Journal Editors (ICMJE) criteria for authorship of this manuscript, takes responsibility for the integrity of the work as a whole, and has given final approval for the version to be published.

open Access: This article is published under the Creative Commons Attribution Non-commercial License, which permits any non-commercial use, distribution, adaptation, and reproduction provided the original author and source are given appropriate credit. (c) The Author 2018.

Received: October 8, 2018

Published Online: November 6, 2018

Citation: US Neurology. 2018;14(2):80-1

Corresponding Author: Jeffrey M Katz,

North Shore University Hospital, 300 Community Drive Manhasset, NY 11030, US. E: JKatz2@northwell.edu

Support: No funding was received in

the publication of this article.
A bout $85 \%$ of strokes are ischemic, and the most severe ischemic strokes are caused by large vessel occlusion due to either artery-to-artery embolism or cardiac embolism. Early treatment is essential to rescue potentially salvageable tissue. ${ }^{1}$ Until recently, the only proven treatment for acute ischemic stroke was intravenous thrombolysis with recombinant tissue-type plasminogen activator (tPA). However, since December 2014, several randomized controlled trials have demonstrated the efficacy and safety of mechanical endovascular thrombectomy. ${ }^{2-7}$ The clinical benefit of endovascular thrombectomy when performed within 6 hours after the onset of stroke symptoms is now well established. ${ }^{8}$ Recently, two clinical trials found that this time window could be extended in patients selected based on computed tomography (CT) perfusion imaging analyzed with RAPID software [iSchemaView, Inc., Menlo Park, CA, US]. The DAWN study found that in people who have relatively small ischemic cores and occlusion of either the intracranial internal carotid or the proximal middle cerebral artery, endovascular therapy at 6-24 hours post-stroke onset plus medical therapy produced better functional outcomes at 90 days compared with medical therapy alone. ${ }^{9}$ In DEFUSE-3, patients with large vessel strokes with favorable ischemic core to penumbra ratios, endovascular therapy at $6-16$ hours post stroke onset, in addition to medical therapy, improved functional neurological outcome at 90 days, compared with medical therapy alone..$^{10}$ In an expert interview, Jeffrey M Katz discusses these advances in stroke treatment.

\section{Q. What have the DAWN and DEFUSE-3 clinical trials taught us about the benefits of endovascular thrombectomy within 6-24 hours of stroke onset?}

These two trials have brought about a huge paradigm shift. Prior to the publication of these trials, most were treating stroke patients up to 6 hours from last known well time. For patients with stroke symptoms beyond 6 hours, we would not intervene to stop the stroke progression and had minimal impact on patient outcome; we would just treat them medically with standard post-stroke hospital care. For instance, if someone went to sleep at 10:00 pm, woke up with a deficit at 6:00 am and reached the hospital at 6:30 am, we would not have treated them, since it could have been over 8 hours since the onset of the stroke. Now we can intervene in selected patients even up to 24 hours, enabling us to help more patients. 


\section{Q. Which patients will benefit from delayed endovascular treatment?}

The patients most likely to benefit are patients who wake up with stroke symptoms, because we do not know what time their stroke started. It will also help patients who have taken some time to get to a hospital that provides endovascular stroke therapy, and arrive outside the previously limited 6-hour treatment window.

\section{Q. What are the most promising developments in mechanical methods of thrombus removal in acute stroke?}

Stent retrievers and suction catheters have been available for more than 5 years now. ${ }^{2,11-13}$ The great thing is that the devices and, as importantly, the techniques have evolved since then, resulting in incredibly high technical success rates that a decade ago were unachievable. Two embolectomy techniques are particularly useful. The simplest is to put a suction catheter up to the clot and suck it out. This is called the ADAPT technique. The other method, and my personal preference, is to combine a suction catheter placed proximal to the clot with a stent retriever, i.e., a stent that is attached to a microguidewire, across and past the clot. This is known as the Solumbra technique; combines the name for a commonly used stent retriever Solitaire (Medronic, Inc., Minneapolis, MN, US) and the commonly used suction catheter made by the company Penumbra (Alameda, CA, US). Before these devices and techniques, we had maybe a 50\% chance of opening up a blocked artery, now it is close to $95 \%$. The procedures are also much shorter than in the past, and as is commonly stated, time is brain. For every $30 \mathrm{~min}$ delay in reperfusion, the patient has a more than $10 \%$ decreased chance of a functional outcome. ${ }^{1}$ In many cases, we can now open up these arteries in less than 30 minutes from skin incision. Despite all of these breakthroughs, leading to shorter treatment times and high rates of technical success, only about half of patients treated actually attain a functional outcome by 90 days post stroke onset. ${ }^{-5}$ Therefore, we still have plenty to do in terms of protecting the brain before the artery is opened, preventing secondary damage once the artery is re-opened, and from a systems perspective, getting the right patients to the right center expeditiously.

\section{Q. What have been the findings of studies investigating the use of 3K3A-APC as an adjuvant to tissue plasminogen activator (tPa)?}

Activated protein $\mathrm{C}$ (APC) is a naturally occurring enzyme with anticoagulant and cytoprotective properties. Genetically modified for functional enhancement, it is being investigated as a neuroprotectant to reduce inflammation and some of the secondary damage that occurs during and after a stroke. It is still at the experimental stage and has not yet been fully investigated in randomized controlled trials, but shows the potential to protect the brain while it is ischemic, ${ }^{14}$ and in a phase 2 study, appeared to reduce the risk of brain bleeding following stroke treatment with tPA and/or mechanical embolectomy. ${ }^{15}$ The hope is that we can use a medicine, potentially like $3 \mathrm{~K} 3 \mathrm{~A}-\mathrm{APC}$, to protect the ischemic brain prior to and post reperfusion. Finding an effective neuroprotectant will be the next leap in stroke care and has the greatest chance of raising the likelihood of excellent clinical outcomes following large vessel occlusion ischemic stroke.

\section{Q. Which other clinical trials for stroke treatment have particularly excited you this year?}

Other studies are looking at expanding the indications for intervention: current US guidelines state that mechanical embolectomy is indicated for large artery occlusion i.e., the first part of the middle cerebral artery and carotid artery. ${ }^{16}$ Ongoing clinical trials are looking at smaller vessels and other vessels that may benefit from embolectomy. In addition, we exclude patients based on other characteristics such as the early infarct signs on pre-treatment CT scans. New studies are looking at intervening in patients with poorer looking pre-treatment CT scans.

If a patient has a baseline disability related to a previous stroke, they are excluded based on national guidelines. New studies are investigating the benefits of interventions in these patients as well.

Expanding the time window has been done; we are now looking at expanding the indications and removing contraindications. $\square$
1. Khatri P, Yeatts $S D$, Mazighi $M$, et al. Time to angiographic reperfusion and clinical outcome after acute ischaemic stroke: an analysis of data from the Interventional Management of Stroke (IMS III) phase 3 trial Lancet Neurol. 2014:13:567-74.

2. Evans MRB, White P, Cowley P, Werring DJ. Revolution in acute ischaemic stroke care: a practical guide to mechanical thrombectomy. Pract Neurol. 2017;17:252-65.

3. Berkhemer OA, Fransen PS, Beumer D, et al. A randomized trial of intraarterial treatment for acute ischemic stroke. N Engl J Med. 2015;372:11-20.

4. Campbell BC, Mitchell PJ, Kleinig TJ, et al. Endovascular therapy for ischemic stroke with perfusion-imaging selection N Eng/ J Med. 2015:372:1009-18.

5. Goyal M, Demchuk AM, Menon BK, et al. Randomized assessment of rapid endovascular treatment of ischemic stroke. N Eng/ J Med. 2015;372:1019-30.

6. Jovin TG, Chamorro A, Cobo E, et al. Thrombectomy within 8 hours after symptom onset in ischemic stroke. N Engl J Med. 2015;372:2296-306.

7. Saver JL, Goyal M, Bonafe A, et al. Stent-retriever thrombectomy after intravenous t-PA vs. t-PA alone in stroke. N Eng/ J Med. 2015;372:2285-95

8. Goyal M, Menon BK, van Zwam WH, et al. Endovascular thrombectomy after large-vessel ischaemic stroke: a meta-analysis of individual patient data from five randomised meta-analsis of individual patient

9. Nogueira RG, Jadhav AP, Haussen DC, et al. Thrombectomy 6 to 24 hours after stroke with a mismatch between deficit and infarct. N Engl J Med. 2018;378:11-21.

10. Albers GW, Marks MP, Kemp S, et al. Thrombectomy for stroke at 6 to 16 hours with selection by perfusion imaging. N Eng/ I Med. 2018;378:708-18

11. Penumbra Pivotal Stroke Trial Investigators. The penumbra pivota stroke trial: safety and effectiveness of a new generation of mechanical devices for clot removal in intracranial large vessel occlusive disease. Stroke. 2009;40:2761-8.

12. Saver JL, Jahan R, Levy El, et al.; SWIFT Trialists. Solitaire flow restoration device versus the Merci Retriever in patients with acute ischaemic stroke (SWIFT): a randomised, parallel-group, non-inferiority trial. Lancet. 2012;380:1241-9.

13. Nogueira RG, Lutsep HL, Gupta R, et al.; TREVO 2
Trialists. Trevo versus Merci retrievers for thrombectom revascularisation of large vessel occlusions in acute ischaemic stroke (TREVO 2): a randomised trial. Lancet. 2012:380:1231-40

14. Williams PD, Zlokovic BV, Griffin JH, et al. Preclinical safety and pharmacokinetic profile of 3K3A-APC, a novel, modified activated protein C for ischemic stroke. Curr Pharm Des. 2012;18:4215-22.

15. Lyden P, Coffey CS, Cudkowicz M, et al.; RHAPSODY Investigators. Final results of the RHAPSODY trial. Presented at: American Heart Association/American Stroke Association 2018 International Stroke Conference, Los Angeles, CA, US, January 24-26, 2018. Abstr. \#LB18. Available at: https:// professional.heart.org/idc/groups/ahamah-public/@wcm/@ sop/@scon/documents/downloadable/ucm_498747.pdf (accessed October 18, 2018)

16. Powers WJ, Rabinstein AA, Ackerson T, et al. 2018 Guidelines for the early management of patients with acute ischemic stroke: a guideline for healthcare professionals from the American Heart Association/American Stroke Association. Stroke. 2018;49:e46-110. 